\title{
Zur Ökophysiologie, Sexualität und Populationsgenetik litoraler Gammaridea - ein Überblick
}

\author{
H.-P. Bulnheim \\ Biologische Anstalt Helgoland (Zentrale); Notkestr. 31, D-W-2000 Hamburg 52, \\ Bundesrepublik Deutschland
}

\begin{abstract}
On ecophysiology, sexuality and population genetics of littoral Gammaridea - a survey. Comparative investigations on the physiological capacities in the euryhaline amphipods Gammarus locusta, G. oceanicus, G. salinus, G. zaddachi and G. duebeni were reviewed. In order to assess the adaptations of these species to the abiotic conditions of their environment, the following criteria were examined: oxygen consumption in relation to ambient salinity and temperature levels, respiratory responses following osmotic stress, resistance capacities to oxygen deficiency, resistance to aerial exposure and the simultaneous presence of hydrogen sulphide. Covering the range from marine to typically brackish-water inhabitants, the 5 species show adaptive responses in the abovementioned order. Respiration is less intensely modified by external factors, and oxygen consumption decreases. Accompanied by faster rates of acclimation to new steady states of performance, resistance capacities increase. The significance of the findings obtained is discussed in relation to the environmental requirements of the amphipods considered. Based on breeding experiments, the sex-determining systems reported thus far in Gammarus species are outlined. As demonstrated in $G$. duebeni, a more or less pronounced influence of external factors such as photoperiod may become effective. A preponderance of males was noted when offspring were raised under long-day photoperiods, whereas females prevailed under short-day conditions. In terms of the critical daylength, the light per day was estimated as being between 13 and $14 \mathrm{~h}$ (Elbe estuary population). Feminizing microsporidians (Octosporea effeminans, Thelohania herediteria), which are transovarially transmitted, can interfere with the system of sex determination and sex differentiation of the host. As reflected in various $G$. duebeni populations, they cause a maternally transferred sex-ratio condition by the production of all-female broods, thereby mimicking extrachromosomal inheritance. An increase of the salinity level to 25-30\% results in a disappearance of $O$. effeminans. In both microsporidians, long exposure to low temperatures $\left(\leq 4^{\circ} \mathrm{C}\right)$ produces eggs which are not all parasitized. Furthermore, intersexuality can be induced by changing environmental factors. Microsporidian species have no influence on sex differentiation in $G$. duebeni celticus, $G$. salinus, $G$. locusta and G. pulex. Patterns of relative electrophoretic mobilities of proteins and the distribution of allele frequencies at polymorphic gene loci can be utilized for species diagnosis and for the evaluation of the relationships between different taxa, particularly at and below the species level. As exemplified by studies on several gammarids from marine, brackish and freshwater environments, inter- and infraspecific gene-enzyme variation is described. Electrophoretic investigations on natural populations of the euryhaline amphipods G. zaddachi, G. salinus, G. tigrinus and others from different geographic areas provided evidence of considerable biochemical genetic variation. In Talitrus saltator- and Talorchestia deshayesii-populations the extent of variability based on microand macrogeographic aspects is illustrated. The large-scale genetic divergence is demonstrated by comparison of samples obtained from the Baltic, North, Atlantic and northern Mediterranean Seas.
\end{abstract}




\section{H.-P. Bulnheim}

\section{EINLEITUNG}

Die Flohkrebse stellen eine ökologisch und taxonomisch vielgestaltige Gruppe der Crustaceen dar, die größtenteils im Meer lebt. Typische und weit verbreitete Repräsentanten bilden die Gammaridae, eine formenreiche Familie, die brackig-marine und limnische Lebensräume besiedelt. Im Bereich von Nord- und Ostsee sind mehrere, nahe miteinander verwandte, euryhaline Gammarus-Arten verbreitet, zu denen $G$. duebeni, G. zaddachi, G. salinus, G. oceanicus, G. locusta und G. tigrinus gehören; letzterer ist erst in neuerer Zeit als Immigrant in schwach brackige Gebiete deutscher Küstengewässer vorgedrungen (vgl. ökologische Übersicht bei Lincoln, 1979). Insgesamt umfaßt die Untersuchung der Gammaridea fast $90 \%$ der bekannten Arten (Bousfield, 1973).

Obgleich morphologisch nur durch sehr wenige Merkmale voneinander getrennt und daher schwer unterscheidbar, erweisen sich die genannten Amphipoden-Arten in ökologischer Hinsicht als zum Teil deutlich voneinander unterschieden. Aufgrund geringer Differenzierungsmerkmale und struktureller Ähnlichkeiten ist das Problem der Artenabgrenzung bis in die 50er Jahre umstritten geblieben und wurde selbst in den 70er Jahren erneut in Frage gestellt.

Der Artenkomplex der Gattung Gammarus bot sich daher als ein Modellfall an, um die Merkmalsdivergenzen anhand verschiedener biologischer Kriterien zu analysieren. Schwerpunkte der Untersuchungen bildeten vergleichende Studien zur Ökophysiologie, zur Geschlechtsbestimmung und Geschlechtsdifferenzierung sowie zur Populationsgenetik. Im Rahmen dieses weitgesteckten Forschungsprogrammes ergaben sich zahlreiche Querverbindungen zu anderen Fachdisziplinen wie z.B. Parasitologie, Entwicklungsbiologie, Endokrinologie, Zytologie, Zoogeographie, Evolutionsgenetik und biochemische Systematik. Weiterführende Untersuchungen an Taxa von Talitridae sowie an marinen Isopoden lieferten ergänzende Befunde zu den populationsbiologischen und ökophysiologischen Fragestellungen.

Die Ergebnisse, die in diesem Zusammenhang erarbeitet wurden, sind in Kontext zu setzen zu den in den letzten Jahren von anderen Autoren vorgelegten Resultaten über Fragen der Habitatselektion, der unterschiedlichen Ressourcennutzung, der Isolationsmechanismen zur interspezifischen Konkurrenzvermeidung, welche trotz überlappender ökologischer Ansprüche durch räumliche und zeitliche Sonderung aufgrund verschiedener Fortpflanzungszeiten ermöglicht wird und zur Koexistenz mehrerer GammarusArten im gleichen Lebensraum (wie z. B. in der Ostsee) geführt hat.

Das Problem der Merkmalsdivergenz bildete Ausgangspunkt und Leitlinie bei der Erforschung der Lebenserscheinungen der oben genannten Gammaridae. Der Untersuchung dieser Krebstiere ist auch deshalb besonderes Augenmerk zugewandt worden, weil sie vielfach in hohen Populationsdichten auftreten und als Fischnährtiere wichtige Zwischenglieder in den Nahrungsketten des aquatischen Litorals bilden. Ihre ökologische Schlüsselstellung dokumentiert sich ferner darin, daß diesen als omnivoren Konsumenten, besonders aber als Verzehrern der Primärproduktion, eine produktionsbiologisch wesentliche Rolle zukommt.

Durch die ganzjährige Verfügbarkeit der in Rede stehenden Gammarus-Arten in ihren Lebensräumen sowie aufgrund der Möglichkeit, diese unter geeigneten Laborbedingungen längerfristig zu hältern und teilweise sogar zu züchten, stellen sie günstige Studienobjekte dar, um spezifische und gemeinsame Merkmale einer verwandtschaft- 
lich sehr eng verbundenen Formengruppe zu analysieren. Darüber hinaus hat sich in letzter Zeit das wissenschaftliche Interesse zunehmend auf diese Krebstiere gerichtet, um deren Eignung als Bioindikatoren und als Versuchsobjekte zur Bewertung der Umweltbeschaffenheit aquatischer Lebensräume umfassend zu prüfen.

Unter Bezug auf die einzelnen Veröffentlichungen, die über Amphipoden in verschiedenen Zeitschriften erschienen sind, werden im folgenden wichtige Ergebnisse, Entwicklungslinien und thematische Verknüpfungen der Forschungsarbeiten zu den vorstehend skizzierten Themenbereichen dargestellt.

\section{ÖKOPHYSIOLOGIE}

Die vorstehend genannten Gesichtspunkte bildeten die Grundlage für ein Untersuchungsprogramm, das darauf zielte, die physiologischen Reaktionen der Kiemen einzelner euryhaliner Gammarus-Arten unter dem Einfluß verschiedener Umweltfaktoren zu erfassen und zu vergleichen. Eine genauere Kenntnis ihrer funktionellen Eigenschaften, wie z. B. des Adaptions- und Regulationsvermögens, sollte dazu beitragen, die ökologischen Ansprüche dieser Arten einem kausalen Verständnis näherzubringen sowie ihre interspezifischen Beziehungen besser zu bewerten. Einen Überblick über diese Thematik lieferte Vernberg (1983), während Sutcliffe (1984) sich den quantitativen Aspekten der Respiration von Gammarus ausführlich und kritisch widmete.

Einen experimentellen Beitrag zu diesem Fragenkomplex stellten vergleichende atmungsphysiologische Studien an den genannten Gammarus-Arten dar. Die im Rahmen dieser Fragestellung durchgeführten Messungen der Atmungsintensität erfolgten auf elektrochemischem Weg in einer kontinuierlich durchströmten Versuchsanlage. Die angewandte Methode gestattete fortlaufende Registrierungen über längere Zeiträume, so daß auch der zeitliche Verlauf von Stoffwechseländerungen erfaßt werden konnte. Zu diesen Zielsetzungen gehörten Untersuchungen über Veränderungen des Sauerstoffverbrauchs während der Häutung, die Beziehungen zwischen $\mathrm{O}_{2}$-Verbrauch, Körpergröße, Salzgehalt und Temperatur, den zeitlichen Verlauf von Anpassungsvorgängen nach einem plötzlichen Wechsel des Salzgehaltes und der Temperatur sowie Vergleiche zwischen Ruhe- und Aktivitätsstoffwechsel.

Da der Einfluß der Häutung auf den respiratorischen Stoffwechsel bislang bei Amphipoden noch nicht untersucht worden ist, wurde diesem Vorgang besondere Beachtung geschenkt. Während des Häutungsgeschehens ist eine vorübergehende Stoffwechselerhöhung um das 2,5-3fache des normalen Niveaus zu verzeichnen. Etwa 4-5 Stunden vor der Häutung (bei $15^{\circ} \mathrm{C}$ ) beginnt der $\mathrm{O}_{2}$-Verbrauch anzusteigen, um zum Zeitpunkt des Abwurfs des Außenskeletts ein Maximum zu erreichen. Danach verringert sich die Atmungsintensität allmählich wieder und erreicht nach etwa 14-16 Stunden die Ausgangswerte. Diese bei allen untersuchten Arten weitgehend gleichartig ablaufenden physiologischen Vorgänge belegen, daß der Häutungsprozeß in der sich ständig wiederholenden Abfolge eine kritische Phase im individuellen Lebenszyklus darstellt. Verschlechterte Umweltbedingungen können daher einen zusätzlichen Streß bewirken, unter dem die beträchtlich gesteigerte respiratorische Aktivität im adulten Stadium sowie andere parallel laufende Stoffwechselvorgänge nicht mehr aufrechterhalten werden können, so daß schließlich der Tod eintritt (Bulnheim, 1972a).

Hinsichtlich der Beziehungen zwischen Stoffwechselgröße und Körpergewicht 
konnten artgebundene Unterschiede und zudem eine Abhängigkeit vom Salzgehalt des Außenmediums nachgewiesen werden. Die Größenabhängigkeit des respiratorischen Stoffwechsels liegt ungefähr im Bereich zwiṣchen einer Gewichts- und einer Oberflächenproportionalität. Wie die unter gleichen experimentellen Bedingungen durchgeführten Messungen gezeigt haben, nimmt die Atmungsintensität in der Reihenfolge von G. duebeni über G. zaddachi, G. salinus, G. oceanicus und G. locusta leicht zu.

Da die untersuchten Gammarus-Arten in brackigen Gewässern mehr oder weniger starken Salzgehaltsschwankungen ausgesetzt sind, interessierte die Frage nach dem Ausmaß ihrer physiologischen Anpassungsfähigkeit an einen plötzlichen Salinitätswechsel. Die gemessenen Änderungen der Atmungsintensität bis zum Erreichen eines gleichbleibenden Niveaus dienten daher als Kriterium für den Ablauf des Anpassungsvorganges an die veränderte Umweltsituation. Es konnte festgestellt werden, daß bei einem Wechsel aus verdünnten in konzentriertere Medien der Anpassungsvorgang an die veränderte Konzentration des Außenmediums wesentlich rascher vonstatten geht und mit geringeren Änderungen der Atmungsintensität verknüpft ist als bei Überführungen in umgekehrter Richtung, wobei eine verstärkte osmoregulatorische Aktivität im Sinne einer Hyperregulation einsetzt. Die einzelnen Arten unterscheiden sich mehr oder weniger deutlich voneinander sowohl in bezug auf das Ausmaß des Stoffwechselanstiegs bzw. -abfalls als auch hinsichtlich der Anpassungszeiten.

Salzgehaltsänderungen können bei Arten, die z. B. in Flußmündungsgebieten leben, in Abhängigkeit vom Gezeitenrhythmus regelmäßig auftreten. Bei einem mehrfachen Salinitätswechsel von $30 \%$ auf $10 \%$ und auf $30 \%$ zurück bleibt der Sauerstoffverbrauch bei G. duebeni - abgesehen von einem kurzfristigen Anstieg ("overshoot") nach den Salzgehaltsänderungen - auf einem annähernd gleichen Niveau. Bei G. locusta, der einen höheren Sauerstoffverbrauch aufweist, erfolgt hingegen nach der Überführung aus einem Außenmedium von $30 \%$ in $10 \%$ eine drastische Stoffwechselsteigerung, die in $30 \%$ wieder rückläufig wird. Der Fähigkeit von G. duebeni, einen plötzlichen Salzgehaltswechsel ohne nachhaltige Änderungen der Stoffwechselintensität zu kompensieren, ist eine adaptive Bedeutung zuzumessen, da diese Art im Gegensatz zu G. locusta häufig in Lebensräumen vorkommt, die starken Veränderungen in der Intensität der abiotischen Umweltfaktoren ausgesetzt sind. Diese unter vergleichenden Gesichtspunkten durchgeführten Experimente haben deutlich gemacht, daß $G$. duebeni über ein besseres Kompensationsvermögen als die anderen Arten verfügt, unter denen G. locusta die geringste Regulationsfähigkeit aufweist. Das weitgehende Fehlen von G. locusta, aber auch von G. oceanicus in Ästuarien mit periodischen Salinitätsfluktuationen findet durch diese Befunde, die auf eine Beanspruchung des Energiestoffwechsels hinweisen, eine physiologische Erklärung.

Weiterhin wurde der Einfluß der Temperatur auf den respiratorischen Stoffwechsel geprüft. Bei allen getesteten Arten liegt eine mehr oder weniger ausgeprägte Abhängigkeit der Größe des Ruhestoffwechsels von der Temperatur vor. Es zeigte sich, daß $G$. locusta bei fast allen Temperaturstufen den relativ höchsten $\mathrm{O}_{2}$-Bedarf aufweist, während sich die anderen Arten wenig voneinander unterscheiden (Bulnheim, 1979).

Auch die Untersuchung der Temperaturadaption führte zu dem Ergebnis, daß sich G. locusta deutlich von den anderen Arten abhebt. Bei diesen Experimenten interessierte der zeitliche Ablauf des Adaptationsprozesses, d.h. das Abklingen der Schockreaktion nach einem plötzlichen Temperaturwechsel bis zum Erreichen eines stationären Gleich- 
gewichtszustandes. Die Änderungen der $\mathrm{O}_{2}$-Verbrauchswerte bis zur Einstellung auf ein neues Stoffwechselniveau dienten als Vergleichsbasis. Das Resultat dieses Versuches machte deutlich, daß die Anpassungsvorgänge als Funktion der Zeit bei G. oceanicus, G. salinus, G. zaddachi und G. duebeni annähernd den gleichen Verlauf zeigen, sich jedoch wesentlich rascher als bei $G$. locusta vollziehen.

Da sich in bestimmten Lebensräumen, die von den genannten Formen besiedelt werden, das Sauerstoffangebot bei einer Verschlechterung der Umweltbedingungen (Abwassereinflüsse, Eisbedeckung in abgeschlossenen brackigen Flachwassergebieten etc.) erheblich verringern kann, wurde das Resistenzvermögen der einzelnen Arten in sauerstoffarmem Milieu geprüft. Der interspezifische Vergleich anhand der mittleren Überlebensraten erbrachte divergierende Ergebnisse: Die Resistenz gegenüber einer stark erniedrigten Sauerstoffkonzentration steigt von $G$. locusta über G. oceanicus, $G$. salinus, G. zaddachi bis zu G. duebeni beträchtlich an.

Bei einer Abnahme des Sauerstoffangebotes verrnögen Gammariden eine Zeitlang durch intensivierte Ventilationsbewegungen der Pleopoden ihren $\mathrm{O}_{2}$-Verbrauch über einen verhältnismäßig weiten Bereich konstant zu halten. Die kritische $\mathrm{O}_{2}$-Spannung, bei welcher der $\mathrm{O}_{2}$-Verbrauch vom Angebot im umgebenden Medium abhängig wird, liegt unterhalb eines $\mathrm{pO}_{2}$ von 30 Torr (bei $15^{\circ} \mathrm{C}$ und $10 \% \mathrm{~S}$ ). Obgleich die getesteten fünf Species ein weitgehend übereinstimmendes Regulationsvermögen zeigen, dokumentieren sich erhebliche Unterschiede in ihrer Resistenz gegenüber längere Zeit einwirkenden sauerstoffarmen Milieubedingungen.

In gleicher Weise werden die abgestuften Resistenzeigenschaften auch bei Sauerstoffarmut und Gegenwart von $\mathrm{H}_{2} \mathrm{~S}$ offenbar. Eine derartige Situation, die im Experiment simuliert worden ist, kann sich in bodennahen Wasserschichten (besonders in der Ostsee unter den Bedingungen von Temperatur- und Salzgehaltsschichtungen in der Wassersäule) noch stärker belastend auf die Lebensbedingungen auswirken (Bulnheim, 1984b).

Unterschiedliches Resistenzvermögen wurde in ähnlicher artspezifischer Abstufung auch bei einem anderen Experiment offenbar, das die Umweltsituation im Gezeitenbereich während des Trockenfallens bei Niedrigwasser simulierte. Nach Exposition in einer feuchten, wasserdampfgesättigten Kammer überlebte $G$. duebeni die anderen Species um ein Mehrfaches bezogen auf die mittleren Überlebenszeiten.

Die im Rahmen dieser Untersuchung erzielten Resultate fügen sich ein in das ökologische Gesamtbild, das über die Umweltansprüche der einzelnen Arten gewonnen worden ist, und bieten u. a. eine Erklärung für ihre abgestufte vertikale Verteilung im gezeitenbeeinflußten Litoral. Das besondere Resistenzvermögen befähigt G. duebeni, auch im Supralitoral unter ungünstigen abiotischen Bedingungen zu existieren. Während $G$. locusta nur bis zum unteren Eulitoral anzutreffen ist, dringen die anderen resistenteren Formen ungefähr bis zur mittleren Gezeitenzone in den Küstenregionen vor.

\section{SEXUALITÄT}

Fragen der Geschlechtsbestimmung, Geschlechtsdifferenzierung und intersexuellen Entwicklung sind bei Gammarus duebeni, G. zaddachi und G. locusta eingehend untersucht worden. Diese Forschungsarbeiten haben das Vorliegen außerordentlich komplexer Verhältnisse deutlich gemacht, wodurch sich das generelle Bild über die Sexualitätserscheinungen bei Crustaceen beträchtlich erweitert hat. 
Ausgehend von früheren Befunden verschiedener Autoren, nach denen beträchtliche Abweichungen vom 1:1-Verhältnis der Geschlechter in Freilandpopulationen und bei den Nachkommen von Paarkulturen nachgewiesen werden konnten, wurde der Versuch unternommen, Natur und Wirkung geschlechtsbeeinflussender Faktoren vor allem bei $G$. duebeni zu analysieren. Die Erkenntnisse, die im Verlauf dieser Untersuchungen gewonnen wurden, führten zu gänzlich neuen Auffassungen über die Bestimmung und Vererbung des Geschlechts bei diesem Flohkrebs, die bei Ginsburger-Vogel \& Charniaux-Cotton (1982), Bull (1983), Ginsburger-Vogel (1985), Legrand et al. (1987) und Korpelainen (1990) zum Teil zusammengefaßt sind.

Primär war die Frage offen, ob neben genetischen Faktoren auch Außeneinflüsse das Zahlenverhältnis von $\nmid \uparrow$ zu $\delta^{0} 0$ festlegen können. Die Einflüsse der Temperatur auf das Geschlechtsverhältnis (z. B. Kinne, 1959) konnten anhand der Zuchtverhältnisse bei G. duebeni, wie sorgfältig angelegte Nachprüfungen ergeben haben, nicht bestätigt werden. Da unter den in Betracht kommenden Milieufaktoren die Rolle des Lichts bisher nicht geprüft worden war, lag es nahe, die Bedeutung unterschiedlicher Tageslängen als eine endogene Rhythmik zu untersuchen.

Um diese Frage experimentell zu klären, wurden Versuche mit zwei verschiedenen Photoperioden, einem zyklischen Licht-Dunkel-Wechsel von LD 8:16 (Kurztag) und LD 16:8 (Langtag), durchgeführt. Bei den jeweils halbierten und zur einen Hälfte unter Kurztags-, zur anderen Hälfte unter Langtagsbedingungen aufgezogenen Würfen zeigte sich, daß im 8:16-Stunden-Tag die Zahl der Weibchen, im 16:8-Stunden-Tag die Zahl der Männchen beträchtlich erhöht ist. Damit konnte der Nachweis geführt werden, daß die Geschlechtsausprägung bei $G$. duebeni von der Tageslänge beeinflußt wird. Die Tatsache, daß Unterschiede verzeichnet wurden, indem von Paar zu Paar eine stärkere oder schwächere Verschiebung des Geschlechtsverhältnisses der Nachkommen nachgewiesen werden konnte, deutet auf eine Abhängigkeit von der genetischen Konstitution der Elterntiere hin (Bulnheim, 1966, 1967b, 1969).

Weiterführende Studien galten der Frage nach der Wirkung unterschiedlicher Lichtintensitäten sowie der kritischen Photoperiode. Eine Reihe von Experimenten mit noch stärker differenzierten Licht-Dunkel-Rhythmen erbrachte das Resultat, daß bei der untersuchten Population des Elbe-Ästuars $\left(53^{\circ} 45^{\prime} \mathrm{N}\right)$ die kritische Photoperiode zwischen LD 13:11 und LD 14:10 liegt. In gemäßigten Breiten ist daher die Dauer von tagesperiodischen Umweltsignalen mit ihren jahreszeitlichen Änderungen ein wichtiger saisonaler Milieufaktor.

Ferner interessierte es, die photosensible Phase näher definieren zu können. Diese umfaßt das geschlechtlich indifferente Stadium, innerhalb dessen unterschiedliche Photoperioden wirksam werden. Durch ein abgestuftes Versuchsprogramm konnte schließlich als kritische Periode die postembryonale Phase zwischen der 2. und 4. Häutung (unmittelbar vor dem Beginn der sexuellen Differenzierung) ermittelt werden (Bulnheim, $1967 b, 1978 a)$.

Die Rolle der geschlechtsbeeinflussenden Photoperiode bei $G$. duebeni ist kürzlich bestätigt worden (Adams et al., 1987). Bei einem Vergleich der südenglischen mit der nordenglischen Population zeigte sich, daß nur die letztere eine photoperiodische Beeinflussung des Geschlechtsverhältnisses aufweist. Hinsichtlich der kritischen Photoperiode wird das Verbreitungsgebiet von $G$. duebeni in nördlicher Richtung durch Verlängerung des Langtages beeinflußt (Naylor et al., 1988a, b). 
Bei den meisten Gammarus-Arten beginnt die Diapause im Herbst und endet im Winter oder Frühling. Die Befunde sprechen dafür, daß die Reproduktionszyklen endogener Natur sind. Der Photoperiode kommt die Rolle zu, die Regelung der Vermehrungsvorgänge einzugrenzen. Die Vitellogenese wird z. B. durch Kurztagsbedingungen bei $G$. setosus und durch Langtagsbedingungen bei G. lawrencianus ermöglicht (Steele \& Steele, 1986).

Weitere Untersuchungen galten dem Problem der Thelygenie, der Entstehung rein weiblicher Linien bei $G$. duebeni. Es handelt sich hierbei um eine recht eigentümliche Erscheinung insofern, als bestimmte $q q$ stets oder fast ausschließlich nur Tochtertiere produzieren, unabhängig davon, mit welchen ơ diese Individuen gepaart werden. Die Eigenschaft, nur $q q$ hervorzubringen, wird also mütterlich vererbt und bleibt bei allen Folgegenerationen unverändert erhalten. Dieser Sachverhalt wurde als ein Fall von plasmatischer Vererbung gedeutet (Traut, 1962). Die eingehende Analyse dieses Problems führte zu der überraschenden Feststellung, daß die Eigenschaft der Thelygenie durch Mikrosporidien bedingt ist, welche über die Eizellen auf die Nachkommen übertragen werden. Diese Mikroorganismen parasitieren in den Keimdrüsen der $q q$ und entwickeln sich in den heranwachsenden Eizellen sowie im umliegenden ovarialen Gewebe. Alle Nachkommen, die aus befallenen Eiern entstehen, differenzieren sich zu \$. Die Erzeugung eingeschlechtlicher Würfe - bedingt durch eine kontinuierliche Weitergabe der Mikrosporidien auf die Nachkommen - konnte über 8 Generationen hinweg verfolgt werden, ohne daß sich die Eigenschaft der Thelygenie abschwächt (Bulnheim, 1967a, 1969, 1970, 1972b).

Die Beziehungen zwischen Mikrosporidieninfektion und Geschlechtsbestimmung konnten durch eine experimentelle Infektion parasitenfreier weiblicher Tiere und Ermittlung des Geschlechtsverhältnisses ihrer Nachkommen bewiesen werden. Da sich eine Neuinfektion durch Verfüttern von Ovargewebe, welches die Mikrosporidien enthielt, nicht herbeiführen ließ, wurde der Versuch unternommen, infiziertes Ovargewebe in die Leibeshöhle mikrosporidienfreier weiblicher Flohkrebse zu übertragen. Sofern diese Individuen den operativen Eingriff überstanden hatten, wurden sie mit $\delta \hat{\delta}$ verpaart und zur Zucht angesetzt. Nach der Operation waren tatsächlich alle oder fast alle abgelegten Eier infiziert und es trat - bezogen auf die Kontrollgruppe - in den Nachkommenschaften eine starke bzw. sogar vollständige Verschiebung des Geschlechtsverhältnisses durch diese "epigenetischen" cytoplasmatischen Faktoren zugunsten der $q q$ zutage.

Die Entwicklung des fraglichen Mikrosporidiums vollzieht sich in den Eizellen sowie in den Follikelzellen und in dem das Ovar umhüllenden Bindegewebe. In männlichen Tieren konnten diese Parasiten hingegen in den vorrangig untersuchten Populationen des Elbe-Ästuars und der Ostseeförde Schlei nicht nachgewiesen werden; sie finden sich jedoch in den Geschlechtsdrüsen von Intersexen, welche - zumeist in geringer Zahl unter den Nachkommen infizierter Tiere auftreten können.

Nachdem die geschlechtsbestimmende Wirkung durch Mikrosporidien anhand von Zuchtexperimenten erkannt worden war, wurden weitere Untersuchungen durchgeführt, um den Entwicklungszyklus, die Taxonomie, die Pathogenität und Wirtsspezifität des Parasiten zu klären. Bei diesem handelt es sich um Octosporea effeminans, eine Species, die eng an G. duebeni gebunden ist; sie konnte in anderen Gammariden nicht gefunden werden. Ihr Entwicklungszyklus (Schizogonie und Sporogonie) vollzieht sich in den Eizellen, Follikelzellen und im ovarialen Bindegewebe. Studien über die Parasit- 
Wirt-Beziehungen, die nach morphologischen und physiologischen Kriterien ausgerichtet wurden, haben gezeigt, daß der Parasit völlig im Wirt integriert ist und - abgesehen von dem geschlechtsbestimmenden Einfluß - keine erkennbare Schadwirkung hervorruft. Neben $O$. effeminans konnte später noch ein zweites Mikrosporidium, eine ebenfalls bislang unbekannte Art, Thelohania herediteria, in weiblichen $G$. duebeni gefunden werden. Auch bei diesem Protozoon ließ sich eine erhebliche Infektion durch transovariale Übertragung und eine geschlechtsdeterminierende Wirkung belegen insofern, als durch Thelohania-Befall die postembryonale Entwicklung ebenfalls in weibliche Richtung gelenkt wird (Bulnheim \& Vávra, 1968; Bulnheim, 1971a).

In ähnlicher Weise wurde festgestellt, daß der Talitride Orchestia gammarellus mit dem Myxozoa Paramarteilia orchestiae (Ginsburger-Vogel \& Desportes, 1979) behaftet ist. Bei diesem intrazellulär lebenden Protozoon wurde nachgewiesen, daß es in Geweben von thelygenen $q q$ und intersexuellen $\delta \delta$ vorkommt. $P$. orchestiae läßt sich auch auf andere Orchestia-Arten übertragen.

Aus diesen Ergebnissen konnte der Schluß gezogen werden, daß es sich bei den Thelygenie-Erscheinungen um Fälle simulierter plasmatischer Vererbung handelt, hervorgerufen durch mütterlich "vererbte" Protozoen. Damit ist bei $G$. duebeni und $O$. gammarellus eine im Tierreich bislang unbekannte Beziehung zwischen einer Infektion mit Parasiten und der Bestimmung des Geschlechts aufgedeckt worden.

Die Frage, inwieweit auch andere Mikrosporidien Einfluß auf die Geschlechtsausprägung ihrer Wirtstiere ausüben, wurde bei Stempellia mülleri sowie bei verschiedenen Thelohania-Arten, die in G. locusta, G. salinus und G. pulex parasitieren, geprüft. Es ergaben sich jedoch keine Hinweise auf eine geschlechtsdeterminierende oder geschlechtsmodifizierende Wirkung dieser Mikrosporidien.

Mit $S$. mülleri, einer in Gammariden der Ostsee aufgefundenen endoparasitischen Species, wurden Laborexperimente u. a. zur Frage der Infektionsweise und Wirtsspezifität durchgeführt. Es konnte festgestellt werden, daß S. mülleri ausschließlich peroral durch Aufnahme von Sporen mit der Nahrung übertragen wird. In der Hinterleibsmuskulatur der Flohkrebse entwickeln sich deutlich abgegrenzte, weißliche Parasitenherde, die bereits makroskopisch eine sichere Diagnose gestatten. $S$. mülleri weist ein breites Wirtsspektrum auf, da mit dieser bisher nur in Süßwasserflohkrebsen nachgewiesenen Mikrosporidie durch perorale Übertragung G. duebeni, G. salinus, G. oceanicus, G. zaddachi und G. locusta experimentell infiziert werden konnten (Bulnheim, 1971b). Hingegen ließen sich perorale Infektionen mit $O$. effeminans und $T$. herediteria nicht erzielen; bei diesen scheint die transovariale Weitergabe der wichtigste Übertragungsmodus zu sein.

Die Frage, in welcher Weise die Mikrosporidien die Geschlechtsdifferenzierung zu beeinflussen vermögen, kann noch nicht hinreichend beantwortet werden. Die Vermutung lag nahe, die Parasiten könnten durch Infektion die androgene Drüse angreifen oder gar zerstören, welche durch Abgabe eines Sexualhormons die Ausbildung der männlichen Geschlechtsmerkmale stenert. Eine Überprüfung von Jungtieren, bei denen die androgene Drüse zunächst nur als paarige Anlage ausgebildet ist, sowie von infizierten Intersexen, welche mehr oder weniger rudimentär entwickelte androgene Drüsen besitzen, erbrachte keine Anhaltspunkte für eine zelluläre Schädigung durch Befall und damit für eine unmittelbare Wirkung der Mikrosporidien auf diese Hormondrüse.

Als ein Beitrag zur Aufhellung der Mechanismen, die der geschlechtsbestimmenden 
Wirkung der Mikrosporidien bei $G$. duebeni zugrunde liegen, wurde der Versuch unternommen, adulte $\delta \hat{\delta}$ dieser Art experimentell zu infizieren, um zu prüfen, ob sich deren sexuelle Organisation nach einer Übertragung der Parasiten verändert. Dieses Experiment gelang sowohl mit $T$. herediteria als auch mit $O$. effeminans, wobei sich herausstellte, daß in den künstlich infizierten männlichen Individuen alle Entwicklungsstadien der beiden Parasiten zur Ausbildung kommen. Während eine Infektion mit $T$. herediteria keine Veränderungen der primären und sekundären männlichen Sexualcharaktere zur Folge hat, bewirkt der Befall mit $O$. effeminans eine Umgestaltung der äußeren männlichen Geschlechtsmerkmale, die nach einigen der Infektion folgenden Häutungen einen intersexuellen Charakter annehmen. Dieser Befund weist darauf hin, daß O. effeminans unmittelbar in den Mechanismus der hormonalen Regulation der Geschlechtsdifferenzierung eingreift und dem von der androgenen Drüse produzierten Wirkstoff, der die Ausbildung der primären und sekundären männlichen Sexualcharaktere steuert, entgegenwirkt (Bulnheim, 1975a, 1977a).

Fernerhin sollten Implantationen der androgenen Drüse in adulte $q$ klären, inwieweit eine Geschlechtsumwandlung nicht nur bei mikrosporidienfreien, sondern auch bei infizierten weiblichen Individuen experimentell ausgelöst werden kann. Diese Versuche führten zu dem Ergebnis, daß sich bei ersteren sowie auch bei $q q$ mit $T$. herediteriaBefall eine totale Vermännlichung innerhalb von etwa 5 Häutungen nach einer Übertragung einer oder mehrerer androgener Drüsen vollzieht. Bei Octosporea-infizierten $q$ q konnte dagegen eine vollständige Maskulinierung nicht erzielt werden. Selbst wenn bis zu 4 androgene Drüsen implantiert wurden, erfolgte nur eine partielle Geschlechtsumstimmung, wobei sich lediglich die sekundären Geschlechtsmerkmale (Propodus der 1. und 2. Pereiopoden, Exopodit der 3. Uropoden) etwas vergröBerten, jedoch nicht das relative Wachstum derjenigen der ot $\delta$ erreichten. Die Gonaden blieben als Ovarien erhalten und erfuhren auch nach langen Versuchszeiträumen keine Transformation zu Hoden.

Diese Experimente erbrachten den Nachweis, daß in Gegenwart des Parasiten $O$. effeminans die physiologische Wirkung des androgenen Hormons nicht voll zum Tragen kommt. Die einzelnen durch diesen Wirkstoff gesteuerten Funktionskreise werden dabei in abgestufter Weise betroffen: Während die gonadotrope Wirkung des männlichen Sexualhormons unterdrückt wird, erfährt das humoral kontrollierte Wachstum der geschlechtsdimorphen Organe (Antennen, Gnathopoden, Uropoden) lediglich eine partielle Hemmung. Hingegen kommt das ebenfalls hormonell stimulierte männliche Sexualverhalten zur Entfaltung, da derartige infizierte Individuen, die nach Implantation androgener Drüsen äußerlich zum Teil sexuell umgestimmt worden sind, präkopulationsbereit gegenüber normalen $\$ q$ waren.

Ausgedehnte Untersuchungen haben gezeigt, daß die beiden Mikrosporidien in unterschiedlichen Prozentsätzen auch in zahlreichen anderen, geographisch getrennten Populationen auftreten, jedoch Unterschiede in den Parasit-Wirt-Beziehungen bestehen. In einer Population von der Ostseeinsel Bornholm konnten Thelygenieerscheinungen lediglich bei Infektionen durch $T$. herediteria nachgewiesen werden, nicht jedoch bei Befall durch $O$. effeminans. Bei der Subspecies G. duebeni celticus (Herkunft: Isle of Man und Bretagne) dagegen kommt - im Gegensatz zu der Unterart G. duebeni duebenieine verweiblichende Wirkung durch Mikrosporidieninfektionen überhaupt nicht zum Tragen: Infektionen durch $O$. effeminans wie auch durch $T$. herediteria konnten in 
beiden Geschlechtern verzeichnet werden. Selbst bei Doppelinfektionen unterbleibt eine Verweiblichung der primären und sekundären Geschlechtsmerkmale des Wirtes. Wie trotz dieser unterschiedlichen Konsequenzen von Mikrosporidieninfektionen für den Wirt einseitige Verschiebungen des Geschlechtsverhältnisses vermieden werden können, ist noch nicht hinreichend geklärt, wie auch andere evolutionsbiologische Fragen offen geblieben sind (Bulnheim, 1978b).

Das gelegentliche Auftreten von Intersexen - sowohl bei den Zuchtstämmen als auch in natürlichen Populationen - führte zu einer eingehenden Analyse der Intersexualitätsphänomene bei $G$. duebeni. Die Bearbeitung dieser Thematik konzentrierte sich auf eine Untersuchung der Geschlechtsmorphologie, des Wachstums, der Häutungsfrequenz, des sexualbiologischen Verhaltens und der Häufigkeit intersexueller Tiere. Unter Einbeziehung der neueren Erkenntnisse über die physiologischen Grundlagen der Geschlechtsdifferenzierung bei den Malakostraken und genetischer Befunde wurde versucht, eine Erklärung für die Entstehung der geschlechtlichen Zwischenformen zu geben (Bulnheim, 1965, 1975b; Charniaux-Cotton \& Payen, 1985).

Die detaillierte Untersuchung intersexueller Individuen führte zu dem Ergebnis, daß nahezu alle Übergangsformen zwischen echten $\$ q$ und echten $\delta \hat{~} \delta$ auftreten können. Diese lassen sich fünf verschiedenen Intersexualitätstypen zuordnen: stark weiblichen, schwach weiblichen, mittleren, schwach männlichen und stark männlichen Intersexen. Diese Klassifizierung basiert auf der abgestuften Ausprägung der primären und sekundären Geschlechtscharaktere (Struktur der Gonaden und der ausführenden Geschlechtsorgane sowie der Oostegiten, Größe und Form der ersten und zweiten Gnathopoden, der ersten und zweiten Antennen sowie der dritten Uropoden).

Stark weibliche Intersexe ähneln habituell und funktionell weitestgehend den normalen $\$$ 우, doch weisen sie gewisse männliche Sexualmerkmale auf. Stärker maskuliniert sind die schwach weiblichen Intersexe, welche im hinteren Bereich des Ovars außerdem testikuläres Gewebe und Anlagen oder mehr oder weniger differenzierte Vesiculae seminalis und Vasa deferentia ausbilden. Diese Tiere sind jedoch steril, da die Ovidukte basal blind geschlossen bleiben, so daß die Eier nicht entlassen werden können. Eine ausgeprägt intermediäre Stellung nehmen die mittleren Intersexe ein. Ihre Gonaden bestehen aus ovarialen und testikulären Bezirken in nicht festgelegter Verteilung und besitzen sowohl mehr oder weniger entwickelte weibliche als auch männliche abführende Geschlechtsorgane. Im allgemeinen sind diese Tiere geschlechtlich nicht funktionstüchtig. Die Oostegiten weisen häufig einen unvollständigen Borstenbesatz auf. Die schwach männlichen Intersexe bilden ebenfalls Oostegiten aus, doch fehlen diesen die Randborsten. Ihre Gonaden stellen Hoden dar, die in ihrem vorderen Bereich entweder auf beiden oder nur auf einer Körperseite kleinere Eizellen enthalten und paarige Oviduktanlagen aufweisen. Einen typisch männlichen Geschlechtsapparat besitzen die stark männlichen Intersexe. Sie tragen zwar Oostegiten ohne Randborsten, doch kann ihre Zahl bis auf eine Brutlamelle reduziert sein. Beide männlichen Intersexualitätstypen sind im allgemeinen fertil.

Hinsichtlich des Wachstums und der Häutungsfrequenz spiegelt sich die intermediäre Stellung der einzelnen Intersexualitätstypen ebenfalls in gradueller Abstufung wider. Bemerkenswert ist vor allem, daß die mittleren Intersexe vielfach ein sexuell ambivalentes Verhalten zeigen. Wie anhand der Präkopulationsbereitschaft festgestellt wurde, können sich diese in Abwesenheit normalgeschlechtlichen Partner als " $\delta \hat{\delta}$ " 
gegen $q 9$ und als " $q 9$ " gegenüber $\delta \delta^{\star}$ verhalten. Diese paarungsbiologische Besonderheit läßt sich als ein Fall von relativer Sexualität interpretieren.

Die intersexuelle Geschlechtsausprägung wịd auf eine rudimentäre Entwicklung der androgenen Drüse und eine damit verbundene unzureichende Hormonproduktion zurückgeführt. Die winzige androgene Drüse, aufgrund ihrer Lage auch Vas-deferensDrüse genannt, stellt die zentrale Bildungsstätte des männlichen Sexualhormons dar, welches die Differenzierung der primären und sekundären männlichen Geschlechtsmerkmale steuert. Da der Grad der Intersexualität vom Entwicklungszustand der androgenen Drüse abhängig ist, wie die histologische Überprüfung der Intersexe gezeigt hat, ist die Schlußfolgerung einer gestörten endokrinen Funktion und einer unzureichenden Produktion des androgenen Hormons naheliegend. Dieser Sachverhalt hat andererseits zur Folge, daß Gonadenbezirke, deren Keimzellen nicht zu männlicher Entwicklung hormonell stimuliert werden können, sich zu Ovarregionen differenzieren. In Analogie zu den von französischen Arbeitsgruppen (vgl. Charniaux-Cotton \& Payen, 1985) eingehend geprüften Verhältnissen bei Talitriden wird auch bei $G$. duebeni eine Selbstdifferenzierung des Ovars angenommen, die nicht hormonell bedingt ist. Das Ovar selbst ist wiederum Bildungsstätte eines weiblichen Sexualhormons, das die Ausbildung der sekundären weiblichen Geschlechtsmerkmale hervorruft. Daraus resultiert die Vorstellung, daß unterschiedliche Konzentrationsverhältnisse der beiden antagonistisch wirkenden Hormone für den Grad der intersexuellen Geschlechtsausprägung bestimmend sind. Für das Entstehen intersexueller Zwischentypen konnte die Beteiligung parasitärer und exogener Faktoren verantwortlich gemacht werden, wobei es schließlich gelang, das Entstehen zwischengeschlechtlicher Formen experimentell zu steuern.

Ausgangspunkt war der Befund, daß Umweltfaktoren wie Salinität und Temperatur für die Lebensfähigkeit der Parasiten eine entscheidende Rolle spielen. Es konnte nachgewiesen werden, daß sich nach einem Salzgehaltsanstieg $(>25-27 \%$ S) O. effeminans (jedoch nicht $T$. herediteria) im Wirtsorganismus nicht mehr zu vermehren vermag und offensichtlich geschädigt wird. Werden infizierte Jungtiere, die geschlechtlich noch nicht differenziert sind, sich normalerweise aber zu 우 entwickeln, vorübergehend einer Salzgehaltsstufe von $25-30 \%$ ausgesetzt, so schlägt eine mehr oder weniger größere Zahl von Individuen eine intersexuelle Entwicklung ein. Sind die Parasiten so weit geschädigt, daß ihre verweiblichende Wirkung unterbleibt, so kann nach Rücküberführung in eine niedrigere Salzgehaltsstufe auch eine rein männliche Differenzierung erfolgen. Das hierbei zutage tretende Geschlechtsverhältnis wird zudem von der während der Postembryonalentwicklung herrschenden Photoperiode beeinflußt, wobei Langtagbedingungen eine männliche Entwicklung begünstigen. Durch erhöhte Salzgehalte läßt sich eine Normalisierung des Mechanismus der Geschlechtsbestimmung erzielen, wodurch bewiesen ist, daß die geschlechtsbeeinflussende Wirkung der Mikrosporidien dem System von genetischen und photoperiodischen Faktoren, welche primär die Geschlechtsrealisation kontrollieren, sekundär überlagert ist (Bulnheim, 1978a). Der prozentuale Anteil der Intersexe in den Nachkommenschaften hängt in erster Linie von der Dauer der Salinitätserhöhung ab. Bezüglich der Ausprägung der einzelnen zwischengeschlechtlichen Merkmale zeigt sich, daß eine kurzfristige Überführung das Entstehen weiblicher Intersexe begünstigt, während eine länger dauernde Einwirkung der höheren Salinität zu einem relativen Anstieg der Zahl männlicher Intersexe führt. Bei 
beiden Mikrosporidienarten bewirkt schließlich eine Verlängerung über Monate $\left(\leqq 4^{\circ} \mathrm{C}\right)$ die Produktion von Eiern, die nicht alle befallen sind.

Nach den inzwischen gewonnenen Ergebnissen läßt sich feststellen, daß intermediäre Exemplare, die sowohl weibliche als auch männliche Gonaden aufweisen, nur in Stämmen mit Octosporea-Infektion auftreten. Eine derartige intersexuelle Entwicklung resultiert somit aus dem Zusammenwirken exogener und parasitärer Einflüsse, wobei der normalerweise wirksame Kippmechanismus bei der sexuellen Differenzierung und ihrer hormonalen Regulation außer Kraft gesetzt wird. Soweit untersucht, kommen bei anderen Arten, die gelegentlich intersexuelle Phänotypen entwickeln (G. locusta, G. salinus, G. pulex), derartige parasitär beeinflußte Vorgänge nicht zum Tragen.

Nachdem zahlreiche Besonderheiten bezüglich der Bestimmung und Vererbung des Geschlechts bei $G$. duebeni aufgedeckt werden konnten, stellte sich die Frage, welche geschlechtsdeterminierende Mechanismen bei den anderen Arten wirksam sind. Zuchtexperimente ließen erkennen, daß bei G. locusta keine signifikanten Abweichungen vom 1:1-Verhältnis der Geschlechter auftreten. Diese Befunde sprechen für das Vorliegen eines Homo-Heterozygotie-Mechanismus, wenngleich Heterochromosomen nicht gefunden bzw, weitere genetische Beweise nicht erbracht werden konnten. Als polyfaktoriell geschlechtsbestimmt hat sich auch G. pulex subterraneus erwiesen, doch unterbleibt offensichtlich eine geschlechtsbeeinflussende Wirkung der Photoperiode (Anders, 1957).

Bei $G$. zaddachi hingegen konnten beträchtliche Abweichungen von der normalen Verteilung der Geschlechter nachgewiesen werden. Es zeigte sich, daß diese zum Teil auf die modifizierende Wirkung unterschiedlicher Tageslängen während der Postembryonalentwicklung zurückzuführen sind. Die Photoperiode, die bei G. locusta keinen Einfluß auf die Geschlechtsverteilung ausübt, wirkt bei G. zaddachi dahingehend, daß bei den im Langtag (LD 16:8) aufgezogenen Brutsätzen vielfach eine relative Zunahme der Männchen zu verzeichnen ist, während unter Kurztagbedingungen (LD 8:16) eine Verschiebung der Zahlenverhältnise zugunsten der Weibchen zutage treten kann. Ähnlich wie bei $G$. duebeni spielen auch genetische Faktoren (wahrscheinlich polygener Art) eine Rolle, so daß die Bestimmung des Geschlechts bei G. zaddachi offensichtlich aus dem Zusammenwirken beider Faktorenkomplexe resultiert (Bulnheim, 1972b).

\section{POPULATIONSGENETIK}

Die Populationsgenetik befaßt sich mit den in Populationen herrschenden Vererbungsgesetzmäßigkeiten und forscht nach den wirksamen Evolutionsfaktoren. Der Genpool von Populationen ist nicht nur von Mutation, Selektion und dem Paarungssystem abhängig, sondern auch von Migration, Isolation, Zufallsdrift und Populationsgröße. Veränderungen des Genbestandes einer Population, die mikroevolutive Prozesse widerspiegeln, bilden daher ein zentrales Arbeitsfeld für experimentelle Fragestellungen und theoretische Überlegungen. Marine Organismen sind erst in jüngerer Zeit in derartige populationsgenetische Studien einbezogen worden. Die nachfolgend skizzierten Untersuchungen über die genetische Bürde, den genetischen Polymorphismus sowie Populations- und Artdifferenzierung bei Amphipoden vermitteln einige Ergebnisse und Probleme aus diesem Forschungsgebiet über die Crustaceen, das übersichtlich durch Hedgecock et al. (1982) dargestellt wurde.

Um Einblicke in das Selektionsgeschehen zu gewinnen, ist es u. a. erforderlich, die 
Fitnesskomponenten einzelner, koexistierender Genotypen zu bestimmen. Die Fitness eines Genotyps bzw. eines Individuums, einer Population oder einer Art setzt sich aus vielen Komponenten zusammen wie Fekundität (Zahl der produzierten Eier), Viabilität (Überlebensrate), Entwicklungsgeschwindigkeit, Paarungserfolg etc. Da es schwierig ist, die absolute Fitness eines Genotyps vollständig zu erfassen, wird als Maß die relative Fitness, der Vergleich mit anderen Genotypen, benutzt. Durch Inzucht kann die Fitness beeinträchtigt werden. In dem Maße, wie diese als Folge der Zunahme des Grades an Homozygotie abnimmt, tritt die genetische Bürde zutage, die auf eine Anhäufung von genetischen Faktoren mit nachteiliger Wirkung zurückzuführen ist und auf dem Wege fortgesetzter Geschwisterpaarung erfaßt werden kann.

Basierend auf umfangreichen Zuchtexperimenten konnten einige quantitative Studien über die Fitness und das Ausmaß der genetischen Bürde bei Gammarus duebeni durchgeführt werden. Unter den Fitnesskomponenten wurden insbesondere die Fekundität, Schlupfrate, Wachstumsintensität und Viabilität untersucht (Bulnheim, 1977b).

Inzucht führt zu einer beträchtlichen Abnahme der relativen Fitness. Bereits nach 3 durch fortlaufende Geschwisterpaarung erzielten Inzuchtgenerationen trat in der Regel ein weitgehender Zusammenbruch der Zuchtstämme zutage. Dieser Befund weist auf das Vorliegen einer hohen Homozygotenbürde hin. Kreuzungen von Individuen aus Inzuchtlinien mit solchen aus nichtverwandten Stämmen oder panmiktischen Populationen bewirkten deutliche Heterosiseffekte bei den Nachkommenschaften. Es muß daher gefolgert werden, daß auch natürliche Populationen eine hohe genetische Bürde tragen. Berechnungen über die Art der genetischen Belastung deuten darauf hin, daß diese vorwiegend als Segregationsbürde (balancierte Bürde) einzustufen ist.

Aus diesern Sachverhalt ergeben sich ökologische Konsequenzen, die für die Besiedlung neuer Lebensräume, vor allem isolierter Brackwasserbiotope, durch G. duebeni von Bedeutung sein dürften. Angesichts der starken Inzuchtdepression wird eine neue Population von nur sehr wenigen Individuen oder gar nur einem Paar kaum erfolgreich begründet werden können, es sei denn, daß sich ein Genfluß aus anderen panmiktischen Populationen durch fortlaufende Zuwanderung von Artgenossen einstellt.

Derartige populationsgenetische Studien sind bisher kaum an wirbellosen Meeresund Brackwassertieren vorgenommen worden. Lediglich Arten der Copepoden-Gattung Tisbe sind mit ähnlicher Fragestellung untersucht worden, wobei sich einige Übereinstimmungen zu den vorstehend angeführten Ergebnissen, insbesondere über Art und Ausmaß der genetischen Bürde, abgezeichnet haben.

Die Methode der elektrophoretischen Proteinauftrennung hat für Untersuchungen über die genetische Variabilität tierischer und pflanzlicher Organismen zunehmende Bedeutung erlangt. Mittels geeigneter Trägersubstanzen und Puffermedien können nach Trennungen im elektrischen Feld sowie durch Anwendung spezifischer Nachweisreaktionen Proteine bzw. Enzyme und ihre Fraktionen in Gestalt charakteristischer Bandenmuster sichtbar gemacht werden. Da Proteine Primärprodukte der Gene darstellen, lassen Ungleichheiten der physikalisch-chemischen Eigenschaften funktionsgleicher Enzyme Rückschlüsse auf genetische Unterschiede zu. Die elektrophoretischen Varianten, die mittels dieser Trenntechnik als multiple Bandensysteme erfaßt werden können und als Allele anzusprechen sind, lassen sich als genetische Marker verwenden. Durch Untersuchungen des Polymorphismus bestimmter Enzyme (Allozyme) ist es möglich geworden, sowohl quantitative Aussagen zur genetischen Variabilität von Populatio- 
nen (Gesamtheit einer Art in einem kontinuierlichen Areal) zu treffen, als auch verwandtschaftliche Beziehungen zwischen verschiedenen Arten und anderen taxonomischen Einheiten biochemisch $\mathrm{zu}$ charakterisieren. Aufgrund der Anwendung dieser enzymspezifischen Nachweisverfahren können systematische und phylogenetische Fragestellungen einer Lösung nähergebracht werden.

$\mathrm{Da}$ es noch keine neuere Zusammenfassung über populationsgenetische Arbeiten an Crustaceen (speziell Amphipoden) gibt, ist es angebracht, die wichtigsten Untersuchungen aufzuführen. Sie entstammen marinen, brackigen und vor allem limnischen Lebensräumen und befassen sich vor allem mit der Vielgestaltigkeit der genetischen Differenzierung, dem Genfluß, den Dendrogrammen und anderen Funktionsprinzipien (Battaglia et al., 1978; Gooch \& Hetrick, 1979; Kolding \& Simonsen, 1983; Borowsky, 1984; Borowsky et al., 1985; Siegismund, 1985a, b, 1988; Siegismund et al., 1985; McDonald, 1985, 1987, 1989; Skadsheim \& Siegismund, 1986; English et al., 1986; Bucklin et al., 1987; Scheepmaker, 1987, 1990a, b; Scheepmaker et al., 1988; Gooch, 1989; Lop \& Oliver, 1989; Paternello et al., 1989; Scheepmaker \& Dalfsen, 1989; Siegismund \& Müller, 1991).

Um inter- und intraspezifische Unterschiede auf biochemisch-genetischer Ebene aufzudecken, wurden mittels vertikaler Stärkegelelektrophorese vergleichende Untersuchungen über die Allozymvariabilität an den Flohkrebsarten Gammarus zaddachi und $G$. salinus durchgeführt. Beide Amphipoden sind angesichts ihrer sehr geringen morphologischen Unterschiede lange Zeit als Subspecies eingestuft worden, bevor ihnen der Rang selbständiger Arten zuerkannt worden ist. Sie weisen eine ähnliche Verbreitung in küstennahen Gewässern Nord- und Nordwesteuropas auf, unterscheiden sich jedoch aufgrund unterschiedlicher Salinitätspräferenz in ihrer Lebensraumbevorzugung. In weiteren Bereichen der Ostsee überdecken sich die Verbreitungsgebiete beider Arten.

Untersuchungen über Enzymausstattung derartiger sympatrischer Populationen haben deutlich werden lassen, daß artspezifische Unterschiede an den folgenden Loci bestehen: Glutamatoxalacetat-Transaminase (GOT) und Argininphospho-Kinase (APK). Dabei erwiesen sich GOT bei $G$. zaddachi und APK bei $G$. salinus als monomorph, während GOT bei G. salinus und APK bei G. zaddachi Polymorphismus zeigten. Unterschiede zwischen diesen Zwillingsarten konnten auch anhand der Allelverteilung am Genlocus für Phosphoglucose-Isomerase (PGI) und Mannosephosphat-Isomerase (MPI) verzeichnet werden (Bulnheim \& Scholl, 1980, 1981b, 1982).

Abgesehen von geringfügigen, auf einzelne Populationen beschränkte Abweichungen ist durch diese Befunde sichergestellt, daß die Struktur- und Funktionseinheiten der Populationen beider Arten fortpflanzungsmäBig isoliert sind. Die aufgetauchten Zweifel an der genetischen Selbständigkeit beider Arten konnten damit zerstreut werden. Die genannten sowie weitere Enzymsysteme weisen gleiche elektrophoretische Mobilitäten auf, wodurch die enge verwandtschaftliche Beziehung beider Formen unterstrichen wird. Die genetische Selbständigkeit konnte auch bei anderen Species der Gattung Gammarus auf enzymelektrophoretischem Weg verifiziert werden.

Parallel zu interspezifischen wurden intraspezifische Vergleiche durchgeführt, wobei - über ein weites Verbreitungsgebiet (Ostsee, Nordsee, Kanalregion) sich erstrekkend-zahlreiche G. zaddachi und G. salinus-Populationen elektrophoretisch untersucht worden sind. Die relativen Häufigkeiten der einzelnen elektrophoretischen Varianten, die als Allelfrequenzen der untersuchten Enzymloci quantifiziert worden sind, dienten 
als Marker für den Populationsvergleich. Anhand ihres Verteilungsmusters lassen sich bei $G$. zaddachi deutliche Unterschiede zwischen den einzelnen Populationen ablesen. Dies ist besonders auffällig bei den Populationen von der französischen oder englischen Küste. Von der französischen Kanalküste bis zur dänischen Westküste ist eine ausgeprägte klinale Variation im APK-Locus zu verzeichnen. Die Bewohner von Ästuarien der Nordsee unterscheiden sich überdies von den Ostseerepräsentanten in den Allelfrequenzen des APK-Locus, wobei die Populationen aus dem Nord-Ostsee-Kanal eine gewisse Übergangsstellung einnehmen. Die genetische Divergenz zwischen den Ostseepopulationen ist dagegen gering (Bulnheim \& Scholl, 1981a).

Bei $G$. salinus bietet sich ein einheitliches Bild. Individuen von Nordseefundorten weisen einen etwas geringeren Grad an Enzympolymorphismus auf als Ostseetiere. Lediglich die Häufigkeitsverteilung der Allele am GOT-Locus zeigt eine gewisse Variabilität.

Um die geographische Variabilität der Allelverteilung bei den genannten polymorphen Enzymloci bewerten zu können, ist u. a. die unterschiedliche Lebensraumbevorzugung und Salinitätstoleranz der beiden Arten in Betracht zu ziehen. Die relativ starke genetische Variabilität bei G. zaddachi deutet darauf hin, daß zwischen geographisch getrennten Populationen vielfach kein ungehinderter Genaustausch stattfindet. Die arttypische Begrenzung des Vorkommens auf Flußmündungsgebiete und andere schwach brackige Gewässer läßt vermuten, daß der für marine Gebiete charakteristische Salzgehalt $(>30 \%$ o) eine starke Barriere für einen kontinuierlichen Genfluß darstellt. Unter der Selektionswirkung der vielgestaltigen Umweltverhältnisse in Ästuar- und Küstengewässern kann es daher zu einer stärkeren genetischen Eigenständigkeit lokaler Populationen kommen. Die weitgehend gleichbleibenden Allozymmuster in den Ostseepopulationen von $G$. zaddachi stützen diese Annahme:, Angesichts des verminderten Salzgehaltes der Ostsee kann eine derartige isolationsfördernde Wirkung in weiten Bereichen dieses brackigen Nebenmeeres ausgeschlossen werden.

Diese Aussage gilt generell für G. salinus, der höhere Salinitäten toleriert und dessen aktive und passive Ausbreitung offensichtlich auch über größere räumliche Distanzen weniger eingeschränkt ist. Dafür spricht die relativ geringere Variabilität der ermittelten Allelfrequenzen.

Weitere Erkenntnisse ergaben sich anhand der Variabilität der Allelverteilung am MPI-Locus, wobei der Differenzierung zwischen Populationen von Ostsee- und NordseeStandorten besondere Beachtung geschenkt wurde. Es zeigte sich bei G. zaddachi, daß Populationen von der westlichen Ostsee einen geringeren Heterozygotiegrad aufweisen als solche von der Deutschen Bucht. Bei G. salinus traten hingegen Unterschiede im Heterozygotiegrad nicht zutage; dagegen weicht bei Ostseetieren die Frequenz der beiden häufigsten MPI-Allele deutlich von der bei Nordseevertretern gefundenen Verteilung ab. Bemerkenswert ist ferner, daß sich die Populationen von $G$. salinus entlang der westlichen Ostsee - besonders innerhalb der Förden - genetisch nicht unwesentlich voneinander differenziert haben. Daraus folgt: Die besondere Gestalt dieser Fördenküste schränkt den Genaustausch zwischen den einzelnen Populationen nachweislich ein und wirkt somit isolationsfördernd.

Um den Differenzierungsgrad zwischen den Arten und anderen Taxa zu quantifizieren, wurden die genetischen Ähnlichkeiten (I) bzw. Distanzen (D) anhand der Allelfrequenzen der untersuchten Loci berechnet. Während die Zwillingsarten (möglicherweise 
Unterarten) G. zaddachi und G. salinus bzw. G. salinus und G. oceanicus ein $I=0,89(17$ Loci) zu verzeichnen haben, repräsentieren die anderen Species der Gattung Gammarus mit einem geringeren $I=0,51-0,38$ echte Artcharaktere (Kolding \& Simonsen, 1983).

Offensichtlich verschleppt durch das Ballastwasser von Schiffen ist der aus Nordamerika stammende euryhaline Flohkrebs G. tigrinus in den dreißiger Jahren erstmalig auf den Britischen Inseln nachgewiesen worden. Nachdem er vor drei Jahrzehnten in industriell versalzten Flußregionen sowie in küstennahen Gewässern Zentraleuropas Fuß gefaßt hat, breitet $G$. tigrinus seinen Lebensraum in brackigen Gewässern der Niederlande und der Bundesrepublik Deutschland zunehmend aus. Diese Arealexpansion nahm einerseits im IJsselmeer und andererseits vom Werra-Weser-System ihren Ausgang und ist in ihrem zeitlichen und räumlichen Ablauf eingehend dokumentiert worden. 1975 konnte G. tigrinus erstmalig in der Ostseeförde Schlei und 1978 im NordOstsee-Kanal nachgewiesen werden (Bulnheim, 1976, 1980). Inzwischen hat sich dessen Expansion im deutschen Faunengebiet fortgesetzt.

Untersuchungen über die Allozymvariabilität wurden bei G. tigrinus in Angriff genommen, um zu klären, ob sich die Populationen der beiden Hauptausbreitungsgebiete biochemisch-genetisch unterscheiden. Um zu Aussagen über deren Beziehungen zueinander zu gelangen, wurde mittels enzymelektrophoretischer Methoden der Grad der genetischen Ähnlichkeit zwischen verschiedenen neugegründeten G. tigrinus-Populationen ermittelt. Ferner wurde angestrebt, anhand der Allelverteilung an polymorphen Enzymloci Hinweise über die räumlich-zeitlichen Veränderungen der genetischen Populationstruktur im Zuge der Arealexpansion zu erhalten.

Als genetische Marker der Populationsdifferenzierung dienten insbesondere drei polymorphe Enzymloci (Phosphoglucose-Isomerase, Mannosephosphat-Isomerase und Phosphoglucomutase), deren elektrophoretische Variabilität an $10 \mathrm{G}$. tigrinus-Populationen quantitativ verglichen wurde.

Der Vergleich machte deutlich, daß sich die meisten Populationen mehr oder weniger stark voneinander differenziert haben. Die größte genetische Verschiedenheit wurde zwischen Populationen nahe des IJsselmeeres und des Nord-Ostsee-Kanals verzeichnet (Bulnheim \& Mühlenkamp, 1982; Bulnheim, 1984a, 1985).

Die Ergebnisse dieser Analyse weisen darauf hin, daß die Besiedlung deutscher und holländischer Gewässer auf Gründerpopulationen unterschiedlicher Herkunft zurückgeht. Sie lassen ferner erkennen, daß es in der Grenzregion zwischen beiden Ländern bereits zu einem Genaustausch zwischen den beiden bislang getrennten Populationseinheiten gekommen ist. Beide Ausgangspopulationen haben im Verlauf ihrer Expansion beträchtliche genetische Differenzierungsvorgänge erfahren. Damit ist ein Beweis erbracht, daß sich die Struktur des Genpools von G. tigrinus bei dem erfolgreichen Vorstoß in neue aquatische Lebensräume, der innerhalb der recht kurzen Zeitspanne von wenig mehr als 2 Jahrzehnten vonstatten ging, erheblich gewandelt hat. Über die Rolle der hierbei beteiligten Faktoren, vor allem der Wirkung von Allelendrift, Zufallsphänomenen und Selektion, lassen sich vorerst nur Mutmaßungen anstellen.

Untersuchungen zur zeitlichen Variabilität bestimmter Gen- und Genotypfrequenzen haben dagegen keine Hinweise auf das Vorliegen größerer Schwankungen erbracht. Bei einer Schlei-Population, die seit mindestens anderthalb Jahrzehnten in dieser Ostseeförde beheimatet ist und von der über den Zeitraum von ca. zehn Jahren (1978-1987) wiederholt Stichproben analysiert worden sind, traten nur geringfügige Veränderungen 
der Allelfrequenzen und des Heterozygotiegrades an den geprüften polymorphen Enzymloci auf.

Um weitere Erkenntnisse über dynamische Prozesse zu gewinnen, die als Folge unterschiedlicher Wirkungen von Selektion, Genfluß, Zufallsdrift und anderer Vorgänge die Populationsstruktur bestimmen, wurden Vertreter der Familie Talitridae, die sich gegenüber den Gammaridae durch eine unterschiedliche Lebensraumbevorzugung auszeichnen, in das Forschungsprogramm einbezogen. Im Rahmen dieser breit angelegten Studie über die genetische Struktur von Populationen der Amphipoden Talitrus saltator und Talorchestia deshayesii wurden sowohl innerartliche als auch zwischenartliche Differenzierungen enzymelektrophoretisch aufgehellt. Beide Krebsarten sind weit verbreitet und als Bewohner des Strandanwurfes an sandige, supralitorale Lebensräume gebunden. Die Untersuchungsgebiete erstrecken sich von der westlichen Ostsee über die Nordsee, die Kanalregion, die französische Atlantikregion (Bulnheim \& Scholl, 1986) sowie neuerdings die portugiesische Küste und den nördlichen mediterranen Raum, wobei das Ausmaß der Variabilität sowohl unter mikrogeographischen als auch makrogeographischen Gesichtspunkten verfolgt wurde.

Unter den 18 eingehend geprüften Enzymloci erwiesen sich vor allem Phosphoglucose-Isomerase (PGI) und Phosphoglucomutase (PGM) als polymorph und daher für den Populationsvergleich geeignet. Einige wichtige Befunde, die auf der Analyse einer Vielzahl von $T$. saltator-Populationen fußen, seien herausgegriffen. Populationen der westlichen Ostsee sind monomorph für PGI, Populationen im Wattenmeerraum der Nordsee dagegen schwach polymorph. Der Anstieg des Polymorphismus in Richtung Kanalregion läßt eine klinale Variation erkennen. Ein zweiter Klin ist bei den Populationen der westfranzösischen Atlantikküste zu verzeichnen. Diese deutlich ausgeprägten Beziehungen im Bestand der Allelfrequenzen legen die ,Vermutung nahe, daß Intensitätsänderungen des Wirkens von Umweltfaktoren (wie der Temperatur) eine selektive Bedeutung für die Ausprägung derartiger Gradienten haben könnten.

Am PGM-Locus ist ein eher irreguläres Verteilungsmuster der elektrophoretischen Varianten feststellbar. Die bisherigen Ergebnisse, die zu einer rechnerischen Abschätzung des Maßes der biochemisch-genetischen Ähnlichkeit geführt haben, weisen darauf hin, daß Genfluß zwischen benachbarten Populationen eine gewisse Rolle spielt, wenngleich die Fähigkeit zu aktiver Ausbreitung bei Talitriden begrenzt ist. Innerhalb der einzelnen Populationen erwiesen sich die Allele durchweg als zufallsgemäß verteilt, es traten also keine Abweichungen vom Hardy-Weinberg-Gesetz auf. Dieser Befund läßt den Schluß zu, daß eine stabile Gleichgewichtssituation besteht und offenbar weder Selektion, Inzucht noch andere Kräfte wirksam sind.

Nach den umfassenden Untersuchungen an den atlantischen Populationen präsentiert sich für die Mittelmeerpopulationen ein völlig anderes Bild, da eine stärkere regionale Differenzierung der Lokalpopulationen zum Tragen kommt. Es ist von besonderem Interesse, daß sich der mediterrane $T$. saltator nach dem Elektrophorenmuster der Enzyme klar abtrennen läßt von dem atlantischen $T$. saltator, indem dieser bei einigen der monomorphen oder allenfalls schwach polymorphen Enzyme (z. B. GOT-2, GPT) andersartige Mobilitäten zur Folge hat (Scholl \& Bulnheim, in Vorbereitung). Diese Befunde machen es wahrscheinlich, daß T. saltator aus der Mittelmeerregion einem Subspecies-Rang zugeordnet werden muß. Dies ist bei $T$. deshayesii-Populationen aus dem nördlichen Mittelmeer nicht oder nicht in gleichem Ausmaß der Fall. 
Die vorstehend geschilderten Studien münden durch das Einbeziehen weiterer Repräsentanten der Gattung Orchestia ein in generelle Vergleiche der genetischen Variabilität zwischen Gammaridae und Talitridae, d.h. zwischen aquatischen und semiterrestrischen Amphipoden. Somit erweist sich der langfristige Formenwandel als aussagekräftige Richtschnur für die weitere Entwicklung genetischer Fragestellungen auf dem Gebiet des Evolutionsprozesses.

\section{AUSBLICK}

Wie aus dem Überblick über die Untersuchungen an Amphipoden hervorgeht, sind in diesem Zusammenhang drei verschiedene Teilaspekte von besonderer Bedeutung. Kernpunkte bilden Fragestellungen der Stoffwechselphysiologie, der Sexualität und der Populationsgenetik. Vielfältige Erkenntnisfortschritte sind bereits zu verzeichnen. Durch wachsende Spezialisierung und Anwendung neuer Untersuchungsmethoden werden die einzelnen Gebiete weiterhin ein interessantes Arbeitsfeld für Meeresbiologen bleiben. Daher wird eine breite und interdisziplinäre Zusammenarbeit mit Sicherheit zu beträchtlichen Fortschritten führen. Angesichts der Vielgestaltigkeit der aufgezeigten Problemstellungen werden sich erneut Tätigkeitsfelder eröffnen, die unsere Kenntnisse über die Biologie brackiger und mariner Organismen küstennaher Lebensräume in Gestalt von Flachwasserbereichen, Gezeitenzonen und Spülsäumen bereichern werden.

\section{LITERATUR}

Adams, J., Greenwood, P. \& Naylor, C., 1987. Evolutionary aspects of environmental sex determination. -- Int. J. Invertebr. Reprod. Dev. 11, 123-136.

Anders, F., 1957. Über die geschlechtsbeeinflussende Wirkúng von Farballelen bei Gammarus pulex spp. subterraneus (Schneider). - Z. Vererbungsl. 88, 291-332.

Battaglia, B., Bisol, P. M. \& Fava, G., 1978. Genetic variability in relation to the environment in some marine invertebrates. In: Marine organisms. Ed. by B. Battaglia \& J. A. Beardmore. Plenum Press, New York, 53-70.

Bousfield, E. L., 1973. Shallow-water gammaridean Amphipoda of New England. Cornell Univ. Press, Ithaca, $312 \mathrm{pp}$.

Borowsky, R., 1984. Environmental control of amylase phenotype in amphipods of the genus Gammarus. - Biol. Bull. mar. biol. Lab., Woods Hole 167, 647-657.

Borowsky, R., Borowsky, B., Milani, H. \& Greenberg, P., 1985. Amylase variation in the salt marsh amphipod Gammarus palustris. - Genetics 111, 311-323.

Bucklin; A., Wilson, R. R. \& Smith, K. L., 1987. Genetic differentiation of seamount and basin populations of the deep-sea amphipod Eurythenes gryllus. - Deep-Sea Res. 34, 1795-1810.

Bull, J. J., 1983. Evolution of sex determining mechanisms. Cummings, London, $316 \mathrm{pp}$.

Bulnheim, H.-P., 1965. Untersuchungen über Intersexualität bei Gammarus duebeni (Crustacea, Amphipoda). - Helgoländer wiss. Meeresunters. 12, 349-394.

Bulnheim, H.-P., 1966. Photoperiodische Beeinflussung des Geschlechtsverhältnisses bei Gammarus duebeni (Crustacea, Amphipoda). - Naturwissenschaften 53, 709.

Bulnheim, H.-P., 1967 a. Mikrosporidieninfektion und Geschlechtsbestimmung bei Gammarus duebeni. - Zool. Anz. (Suppl.) 30, 432-442.

Bulnheim, H.-P., 1967b. Über den Einfluß der Photoperiode auf die Geschlechtsrealisation bei Gammarus duebeni. - Helgoländer wiss. Meeresunters. 15, 69-85.

Bulnheim, H.-P., 1969. Zur Analyse geschlechtsbestimmender Faktoren bei Gammarus duebeni (Crustacea, Amphipoda). - Zool. Anz. (Suppl.) 32, 244-260.

Bulnheim, H.-P., 1970. Einfluß von Mikrosporidien auf die Bestimmung und Vererbung des Geschlechts. - Umschau 70, 782-783. 
Bulnheim, H.-P., 1971a. Entwicklung, Übertragung und Parasit-Wirt-Beziehungen von Thelohania herediteria sp. n. - Z. ParasitKde 35, 241-262.

Bulnheim, H.-P., 1971b. Über den Wirtskreis der Mikrosporidie Stempellia mülleri. - Arch. Protistenk. 113, 137-145.

Bulnheim, H.-P., 1972a. Vergleichende Untersuchungen zur Atmungsphysiologie euryhaliner Gammariden unter besonderer Berücksichtigung der Salzgehaltsanpassung. - Helgoländer wiss. Meeresunters. 23, 485-534.

Bulnheim, H.-P., 1972b. On sex-determining factors in some euryhaline Gammarus species. In: 5 th European Marine Biology Symposium. Ed, by B. Battaglia. Piccin, Padova, 115-130.

Bulnheim, H.-P., 1975a. Intersexuality in Gammaridae and its conditions. - Pubbl. Staz. zool. Napoli 39 (Suppl.), 399-416.

Bulnheim, H.-P., 1975b. Microsporidian infections in amphipods with special reference to hostparasite relationships: A review. - Mar. Fish. Rev. 37, 39-45.

Bulnheim, H.-P., 1976. Gammarus tigrinus, ein neues Faunenelement der Ostseeförde Schlei. Schr. naturw. Ver. Schlesw.-Holst. 46, 79-84.

Bulnheim, H.-P., 1977a. Geschlechtsumstimmung bei Gammarus duebeni (Crustacea, Amphipoda) unter dem Einfluß hormonaler und parasitärer Faktoren. - Biol. Zbl. 96, 61-78.

Bulnheim, H.-P., $1977 \mathrm{~b}$. Effects of inbreeding on the relative fitness of the amphipod Gammarus duebeni Liljeborg. - Crustaceana (Suppl.) 4, 3-14.

Bulnheim, H.-P., 1978a. Interaction between genetic, external and parasitic factors in sex determination of the crustacean amphipod Gammarus duebeni. - Helgoländer wiss. Meeresunters. 31, $1-33$.

Bulnheim, H.-P., 1978b. Variability of the modes of sex determination in littoral amphipods. In: Marine organisms. Ed. by B. Battaglia \& J. A. Beardmore. Plenum Press, New York, 529-548.

Bulnheim, H.-P., 1979. Comparative studies on the physiological ecology of five euryhaline Gammarus species. - Oecologia 44,80-86.

Bulnheim, H..P., 1980. Zum Vorkommen von Gammarus tigrinus im Nord-Ostsee-Kanal. - Arch. FischWiss. $30,67-73$.

Bulnheim, H.-P., 1984a. Biochemisch-genetische Untersuchungen zur Art- und Populationsdifferenzierung bei Amphipoden und Isopoden. - Zool. Beitr. 28, 349-368.

Bulnheim, H.-P., 1984b. Physiological responses of various Gammarus species to environmental stress. - Limnologica 15, 461-467.

Bulnheim, H.-P., 1985. Genetic differentiation between natural populations of Gammarus tigrinus (Crustacea, Amphipoda) with references to its range extension in European continental waters. Arch. Hydrobiol. 102, 273-290.

Bulnheim, H.-P. \& Mühlenkamp, M., 1982. Genetische Variabilität und Ausbreitung von Gammarus tigrinus auf dem europäischen Kontinent. - Verh. dt. zool. Ges. 75, 293.

Bulnheim, H.-P. \& Scholl, A., 1980. Evidence of genetic divergence between two brackish-water gammaridean sibling species. - Mar. Ecol. Prog. Ser. 3, 163-165.

Bulnheim, H.-P. \& Scholl, A., 1981a. Genetic variation between geographic populations of the amphipods Gammarus zaddachi and G. salinus. - Mar. Biol. 64, 105-115.

Bulnheim, H.-P. \& Scholl, A., 1981b. Electrophoretic approach to the biochemical systematics of gammarids. - Helgoländer Meeresunters. 34, 391-400.

Bulnheim, H.-P. \& Scholl, A., 1982. Polymorphism of mannose phosphate isomerase in North Sea and Baltic Sea populations of the amphipods Gammarus zaddachi and G. salinus. - Mar. Biol. 71, $163-166$.

Bulnheim, H.-P. \& Scholl, A., 1986. Genetic differentiation between populations of Talitrus saltator and Talorchestia deshayesii (Crustacea: Amphipoda) from coastal areas of the north-western European continent. - Mar. Biol. 92, 525-536.

Bulnheim, H.-P. \& Vávra, J., 1968. Infection by the microsporidian Octosporea effeminans sp. n., and its sex determining influence in the amphipod Gammarus duebeni. - J. Parasit. 54, 241-248.

Charniaux-Cotton, H. \& Payen, G., 1985. Sexual differentiation. In: The biology of Crustacea. Ed. by D. Bliss. Acad. Press, New York, 9, 252-280.

English, D. S., Alam, T. M. \& Blinn, D. W., 1986. Electrophoretic characterization of Hyalella montezuma: an endemic filter feeding amphipod. - J. Hered. 77, 284-285. 
Ginsburger-Vogel, T., 1985, Le déterminisme du sexe chez les Amphipodes. - Bull. Soc. zool. Fr. $110,49-61$.

Ginsburger-Vogel, T. \& Charniaux-Cotton, H., 1982. Sex determination. In: The biology of Crustacea. Ed. by D. Bliss. Acad. Press, New York, 2, 257-281.

Ginsburger-Vogel, T. \& Desportes, I., 1979. Etude ultrastructurale de la sporulation de Parasarteilia orchestiae gen. n., sp. n., parasite de l'Amphipode Orchestia gammarellus (Pallas). - J. Protozool. $26,390-403$.

Gooch, J. L, 1989. Genetic differentiation in relation to stream distance in Gammarus minus (Crustacea, Amphipoda) in Appalachian watersheds. - Arch. Hydrobiol. 114, 505-519.

Gooch, J. L. \& Hetrick, S. W., 1979. The relation of genetic structure to environmental structure Gammarus minus in a Karst area. - Evolution 33, 192-206.

Hedgecock, D., Tracey, M. L. \& Nelson, K., 1982. Genetics. In: The biology of Crustacea. Ed. by D. Bliss. Acad. Press, New York, 2, 283-403.

Kinne, O., 1959. Ecological data on the amphipod Gammarus duebeni. A monograph. - Veröff. Inst. Meeresforsch. Bremerh. 6, 177-202.

Kolding, S. \& Simonsen, V., 1983. Phylogenetic relationships of five species of the amphipod genus Gammarus. - Zool. Scr. 12, 215-219.

Korpelainen, H., 1990. Sex ratios and conditions required for environmental sex determination in animals. - Biol. Rev. 65, 147-184.

Legrand, J. J., Legrand-Hamelin, E. \& Juchault, P., 1987. Sex determination in Crustacea. - Biol. Rev. 62, 439-470.

Lincoln, R. J., 1979. British marine Amphipoda: Gammaridea. British Museum, London, $658 \mathrm{pp}$.

Lop, A. F. \& Oliver, J. L., 1989. Isozyme differentiation among sibling species and among populations of the Echinogammarus berilloni-group (Crustacea, Amphipoda). - Z. zool. Syst. Evolutionsforsch. 27, 282-292.

McDonald, J. H., 1985. Size-related and geographic variation at two enzyme loci in Megalorchestia california (Amphipoda: Talitridae). - Heredity 54, 359-366.

McDonald, J. H., 1987. Repeated geographic variation at three enzyme loci in the amphipod Platorchestia platensis. - Evolution 41, 438-441.

McDonald, J. H., 1989. Selection component analysis of the Mpi locus in the amphipod Platorchestia platensis. - Heredity 62, 243-249.

Naylor, C., Adams. J. \& Greenwood, P. D., 1988a. Variation in sex determination in natural populations of a shrimp. - J. evolut. Biol. 1, 355-368.

Naylor, C., Adams, J. \& Greenwood, P. D., 1988b. Population dynamics and adaptive sexual strategies in a brackish water crustacean, Gammarus duebeni. - J. Anim. Ecol. 57, 493-507.

Patarnello, T., Bisol, P. M. \& Battaglia, B., 1989. Studies on differential fitness of PGl genotypes with regard to temperature in Gammarus insensibilis (Crustacea: Amphipoda). - Mar. Biol. 102, 355-359.

Sheepmaker, M., 1987. Morphological and genetic differentiation of Gammarus stupendus Pinkster, 1983 in the Massif de la Sainte Baume, France. - Bijdr. Dierk. 57, 1-18.

Sheepmaker, M., 1990a. Genetic differentiation and estimated levels of gene flow in members of the Gammarus pulex-group (Crustacea, Amphipoda) in western Europe. - Bijdr. Dierk. 60, 3-30.

Sheepmaker, M., 1990b. Genetic differentiation, origin and dispersal of Gammarus gauthien from the Iberian peninsula and North Africa (Crustacea, Amphipoda). - Bijdr. Dierk, 60, 31-49.

Sheepmaker, M., van der Meer, F. \& Pinkster, S., 1988. Genetic differentiation of the Iberian amphipods Gammarus ibericus Margalef, 1951 and G. gauthierie S. Karaman, 1935, with reference to some related species in France. - Bijdr. Dierk. 58, 205-226.

Sheepmaker, M. \& Dalfsen, J. van, 1989. Genetic differentiation in Gammarus fossarum and $G$. caparti (Crustacea, Amphipoda) with reference to G. p. pulex in Northwestern Europe. - Bijdr. Dierk. 59, 127-139.

Siegismund, H. R., 1985a. Genetic studies of Gammarus. II. Geographical variation at polymorphic enzyme loci in Gammarus salinus and Gammarus oceanicus. - Hereditas 102, 15-23.

Siegismund, H. R., 1985b. Genetic studies of Gammarus. III. Inheritance of electrophoretic variants of the enzymes mannose phosphate isomerase and glucose phosphate isomerase in Gammarus oceanicus. - Hereditas 102, 25-31. 
Siegismund, H. R., 1988. Genetic differentiation in populations of the freshwater amphipod Gammarus roeseli and Gammarus fossarum. - Hereditas 109, 269-276.

Siegismund, H. R, \& Müller, J., 1991. Genetic structure of Gammarus fossarum populations. Heredity $66,419-436$.

Siegismund, H. R., Simonsen, V. \& Kolding, S., 1985. Genetic studies of Gammarus. I. Genetic differentiation of local populations. - Hereditas 102, 1-13.

Skadsheim, A. \& Siegismund, H. R., 1986. Genetic relationships among northwestern European Gammarida (Amphipoda). - Crustaceana 51, 153-175.

Steele, V. J. \& Steele, D. H., 1986. The influence of photoperiod on the timing of reproductive cycles in Gammarus species (Crustacea, Amphipoda), - Am. Zool. 26, 459-467.

Sutcliffe, D. W., 1984. Quantitative aspects of oxygen uptake by Gammarus (Crustacea, Amphipoda): a critical review. - Freshwat. Biol. 14, 443-490.

Traut, W., 1962. Zur Geschlechtsbestimmung bei Gammarus duebeni Lillj. und verwandten Arten (Crustacea, Amphipoda). - Z. wiss. Zool. 167, 1-72.

Vernberg, F. J., 1983. Respiratory adaptations. In: The biology of Crustacea. Ed, by D. Bliss. Acad. Press, New York, 8, 1-42. 